sciendo

10.2478/aucft-2021-0010

\title{
EFFECT OF COMPLEXATION CONDITIONS ON MICROCAPSULATION OF LACTOBACILLUS CASEI L61 IN GELLAN GUM-CHITOSAN GELS
}

\author{
- Research paper - \\ Fanbo MENG* , Guowei SHU*, Yunxia $\mathrm{HE}^{*}$, Wenhui Li**, Hongxing GUO**, Jiangpeng \\ $\mathrm{MENG}^{1, * *}$
*School of Food and Biological Engineering, Shaanxi University of Science \& Technology, Xi'an, 710021, China;
**Department of Research and Development, Xi'an Baiyue Goat Milk Group Co., Ltd., Xi'an, 710028, China

\begin{abstract}
Probiotics have many benefits for human intestinal health. However, Probiotics have poor tolerance to gastric acid and bile salts of the stomach. Microencapsulation could confer protection to probiotic against harsh environments effectively. In this experiment, Lactobacillus casei L61 was embedded by extrusion with gellan gum and chitosan as wall material. The viable cells and encapsulation yield of microcapsules were used as the indexes, the optimum values of each factor were determined by a single factor experiment. Chitosan concentration $0.50 \%$, chitosan $\mathrm{pH} 4.5$, gellan gum concentration $1.50 \%$, the volume ratio of bacterial suspension to gellan gum is 1:6, the volume ratio of bacterial gum to chitosan is $1: 4$, the stirring time is $40 \mathrm{~min}$.
\end{abstract}

Keywords: Probiotics; Microencapsulation; Lactobacillus casei L61; gellan gum; Chitosan

\section{INTRODUCTION}

There are many definitions of probiotics, depending on how we understand the mechanism of their effects on human health. Generally speaking, probiotics are living microorganisms that can bring benefits to human health after being ingested in sufficient quantities (WHO/FAO, 2001). These beneficial effects include preventing diarrhea, alleviating lactose intolerance, enhancing immunity, promoting digestion and absorption, and lowering cholesterol, etc (Gareth et al., 2016). The most common probiotics are Lactobacillus and Bifidobacterium. Lactic acid bacteria known to be used as probiotics include Lactobacillus plantarum 、 L. delbrueckii subsp. bulgaricus 、 L. gasseri, $L$. johnsonii 、 L. casei 、 L. paracasei 、 L. acidophilus 、 L. reuteri, L.rhamnosus and so on (Solanki et al., 2013). Lactobacillus casei (L.casei) belongs to Lactobacillus genus, gram-positive bacteria. L.casei is widely found in the human oral cavity, intestinal contents, stool, and vagina. While L.casei exists in the intestinal tract, it also helps maintain intestinal balance (Kekkonen et al., 2008). L. casei can

Received: 01.03.2021

Accepted in revised form: 12.05.2021

\footnotetext{
${ }^{1}$ Corresponding author. E-Mail address: byjpmeng@gmail.com
}

produce antibiotics, reduce cholesterol, inhibit the occurrence of cancer, it has an important role in immune regulation (Vishwanathan et al., 2011).

The application of probiotics has been very extensive, and the common probiotics in our life are mainly dairy products. However, the effect of probiotics depends on the survival and reproduction of probiotics in the host. At present, reducing the loss of probiotics in the processing and digestion process is an urgent problem to be solved (Islam et al., 2010). Many new bioculture techniques such as screening resistant strains, adding lyophilized protectant, and microencapsulation has been used to improve the tolerance of probiotics (Sarkar, 2010). At present, in the aspect of probiotics protection technology, microcapsule technology is a research hotspot at home and abroad.

The process of wrapping cells in a membrane to protect cells from harm, reduce cell death, and enable microorganisms to be slowly released in the intestine is called microencapsulation (Sultana et al., 2000). At present, the main methods to prepare microcapsules are extrusion, spray compound condensation (Martín et al., 2015). The drying, emulsion, fluid bed, freeze-drying, and 
first step of preparing probiotics microcapsule is to select suitable wall material, wall materials used in microcapsules are commonly chitosan, carrageenan, alginate, sodium carboxymethyl cellulose, gellan gum, and so on (Martín et al., 2015). There has been a lot of research on the selection of microcapsule wall material. Argin embedded probiotics in xanthan gum-chitosan gel found that xanthan gumchitosan microcapsule can provide good protection for probiotics. In addition, the swelling and release behaviors of xanthan gum-chitosan hydrogel under simulated gastrointestinal conditions were characterized, and it was found that the probiotics were completely released from the gel system within $5 \mathrm{~h}$ in simulated gastric and intestinal fluid (Argin et al., 2014). In addition, the microcapsules of alginate-chitosan and alginate-xanthan gumchitosan have also been studied (Lee et al., 2005; Fareez et al., 2015). Sun fixed Bifidobacterium with gellan gum and xanthan gum. Studies showed that the tolerance of probiotics to the high acid environments was significantly improved after being embedded, and the storage stability in yogurt

\section{MATERIALS AND METHODS}

\section{Microorganism and strain activation}

L.casei L61 was obtained from the College of Food and Biological Engineering, Shaanxi University of Science and Technology (Xi'an, China). The lyophilized powder of L.casei $\mathrm{L} 61$ stored at $-18^{\circ} \mathrm{C}$ was inoculated with $3 \%$ inoculation amount into MRS broth medium and activated twice. After mixing, it was incubated at $37^{\circ} \mathrm{C}$ for $24 \mathrm{~h}$ at a constant temperature. The last time was incubated at the same temperature for $18 \mathrm{~h}$ and stored at $4{ }^{\circ} \mathrm{C}$ for later use.

\section{Preparation of polysaccharide solution \\ Chitosan. An appropriate amount of chitosan (mW $=370 \mathrm{kDa}$ ) was dissolved in $1 \%$ glacial acetic acid solution, and the chitosan solution $\mathrm{pH}$ was adjusted with $\mathrm{NaOH}$ solution after full dissolution.}

Gellan gum. An appropriate amount of gellan gum was weighed and dissolved in $50^{\circ} \mathrm{C}$ deionized water, sterilized at $110^{\circ} \mathrm{C}$ for $10 \mathrm{~min}$, and cooled to $37^{\circ} \mathrm{C}$ for later use.

\section{Preparation of natural polysaccharide microcapsules}

An appropriate concentration of gellan gum solution was prepared, and the solution was dropped into the chitosan solution stirred slowly at $50 \mathrm{r} / \mathrm{min}$ was also significantly improved (Sun et al., 2000). Chitosan is the only natural cationic polysaccharide with good biocompatibility, non-toxicity, and biodegradability. However, the application of single-component polysaccharides is limited due to their poor water resistance and low mechanical strength. As the only natural cationic polysaccharide, chitosan has a positive amino charge in an acidic aqueous solution, which can be complexed with the negative charge of anionic polysaccharide to form cogel. Among the anionic polysaccharides, gellan gum is non-toxic, tasteless, acid-resistant, heat-resistant, insoluble in cold water, and has high stability and gel ability. However, few studies have been done, so chitosan and gellan gum are selected as research wall materials in this study. In this study, L.casei L61 was embedded with chitosan and gellan gum as wall materials. Using the viable cells and the encapsulation yield as indicators, explore the influence of a single factor on the formation of microcapsules, find the best conditions for each factor, and lay a foundation for the optimization of production processes in the future.

with a $5 \mathrm{~mL}$ medical syringe in a dropwise manner. In this process, the height of the needle from the liquid surface of the solution is about $5 \mathrm{~cm}$, and the drop rate is about $3 \mathrm{~mL} / \mathrm{min}$. After stirring for a period of time, the wet capsule was fully complexed, filtered through a sieve, and washed with sterile saline three times to obtain the required wet gellan gum-chitosan hydrogel.

\section{Preparation of gellan gum-chitosan Lactobacillus casei L61 microcapsule}

The activated L.casei L61 was centrifuged to collect the bacteria $(8000 \mathrm{r} / \mathrm{min}, 10 \mathrm{~min})$, washed with $0.9 \%$ sterile normal saline, and centrifuged again to collect the sludge, and $1 \mathrm{~mL}$ of $0.9 \%$ sterile normal saline was used to prepare the bacterial suspension. Gellan gum solution was sterilized at $121^{\circ} \mathrm{C}$ for $15 \mathrm{~min}$, cooled to $37^{\circ} \mathrm{C}$, and mixed with bacterial suspension. A chitosan solution with a certain concentration is obtained by dissolving chitosan in $1 \%$ glacial acetic acid and diluting it. The mixed solution of gellan gum and the bacterial suspension was dropped into a slowly stirred chitosan solution at $37^{\circ} \mathrm{C}$ using a $5 \mathrm{~mL}$ medical syringe in a dropwise manner. In this process, the height of the needle from the liquid level of the solution is about $4 \mathrm{~cm}$, and the drop rate is about $3 \mathrm{~mL} / \mathrm{min}$. After stirring for a certain time, the wet capsule was fully complexed, filtered through a sieve, and washed 
with sterile saline three times to obtain the required wet gellan gum-chitosan L.casei L61 microcapsule. The initial conditions for preparing L.casei L61 microcapsule were $0.5 \%$ chitosan concentration, $\mathrm{pH}$ $4.0,1.5 \%$ gellan gum concentration, the volume ratio of bacterial suspension (VRBS) to gellan gum is $1: 4$, the volume ratio of bacterial gum (VRBG) to chitosan is $1: 4$, and stirring time is $30 \mathrm{~min}$.

\section{Determination of swelling degree}

First, the prepared wet microcapsules need to be freeze-dried. The wet microcapsule was put into the plate, sealed with plastic wrap, and some small holes were made in the plastic wrap. Then, the microcapsule was put into the ultra-low temperature refrigerator and pre-frozen at $\quad-80^{\circ} \mathrm{C}$ for $2 \mathrm{~h}$. After the pre-freezing, the microcapsule was freeze-dried in a vacuum freeze-dryer for $24 \mathrm{~h}$. After freezedrying, the prepared wet microcapsules, the freezedried microcapsules with a certain weight were weighed and placed in $20 \mathrm{~mL}$ deionized water overnight. The microcapsules were filtered and drained of water on the surface for weighing (ArginSoysal et al., 2009). The calculation formula of swelling degree (SR) of the microcapsule is as follows:

$S R(\%)=\frac{W_{s}-W_{f d}}{W_{f d}} \times 100$
where:

Ws - Weight of microcapsules after swelling (g), $\mathrm{W}_{\mathrm{fd}}$ - Weight of freeze-dried microcapsules $(\mathrm{g})$.

\section{RESULTS AND DISCUSSIONS}

\section{Feasibility analysis of gellan gum-chitosan microcapsules}

Gellan gum-chitosan microcapsules were prepared by extrusion and their morphological characteristics were observed to determine the feasibility of using gellan gum and chitosan as wall materials. The results are shown in Figure 1. The microcapsules formed by chitosan and gellan gum are in good shape and uniform in size. Therefore, it is feasible to use these two natural polysaccharides as the wall material of microcapsules.

\section{The viable cells and the encapsulation yield}

The viable cells of L.casei L61 were determined by the plate colony counting method. 1g L.casei L61 microcapsule was placed in $9 \mathrm{~mL} \mathrm{pH} 7.4$ phosphate buffer solution, and then was oscillated in a $37^{\circ} \mathrm{C}$ constant temperature incubator for $10 \mathrm{~min}$. After taking it out, it is homogenized with a high-speed dispersion homogenizer for the 30s, then the homogenate was diluted with sterile normal saline at a gradient of 10 times, diluted to an appropriate ratio, coated on MRS ager medium, sealed, numbered, inverted, and cultured in $37^{\circ} \mathrm{C}$ constant temperature incubator for $48 \pm 2 \mathrm{~h}$. The number of colonies between 30 and 300 was selected, and then the viable cells per unit mass of microcapsule were calculated. Encapsulation yield $(\%)=\frac{N}{N_{0}} \times 100 \%$
where:

$\mathrm{N}$ - Total viable cells in the microcapsule,

$\mathrm{N}_{0}$ - Total viable cells in the original bacteria solution before embedding.

\section{Single-factor experiment}

The single factor experiment was designed to investigate how each factors affect gellan gumchitosan L.casei L61 microcapsule with the viable cells and the encapsulation yield as the indexes. Each factor level is as follows: Chitosan concentration: $0.25 \%, 0.5 \%, 0.75 \%, 1 \%$; Gellan gum concentration: $1.00 \%, 1.25 \%, 1.50 \%, 1.75 \%$; Chitosan pH: 4.0, 4.5, 5.0, 5.5, 6.0; VRBS to gellan gum: 1:2, 1:4, 1:6, 1:8; VRBG to chitosan: 1:3, 1:4, 1:5, 1:6.

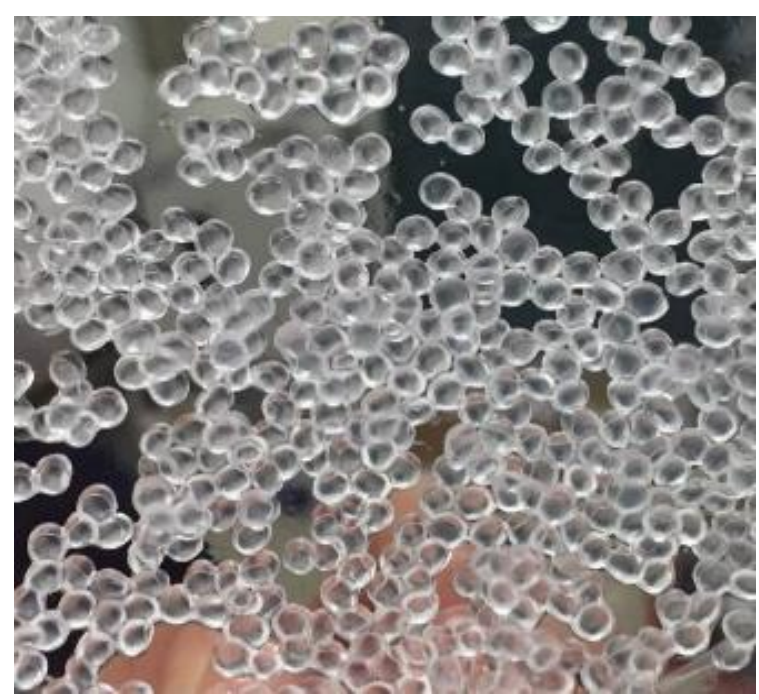

Figure 1. GG-CS microcapsules (GG:gellan gum CS:chitosan) 
Effect of preparation conditions on the swelling degree of gellan gum-chitosan microcapsules

The swelling property has an important influence on the protective effect and controlled release function of microcapsules. The swelling speed and water absorption degree of microcapsules in solution were studied to investigate the influence of the change of crosslinking degree of the substrate on the release of the core material. The swelling process is easily affected by the properties of the polymer such as the molecular weight of chitosan. The $\mathrm{pH}$ of chitosan solution and complexing time will also affect the swelling process and determine the crosslink density of the complex. The swelling rule was mainly characterized by the swelling degree. The effects of preparation conditions such as the gellan gum concentration $(0.7 \%, 1.0 \%, 1.5 \%)$, the chitosan concentration $(0.7 \%, 1.0 \%)$, and the chitosan $\mathrm{pH}$ $(4.5,5.5,6.2)$ on the swelling degree of microcapsules were studied experimentally. The results were shown in Figure 2.
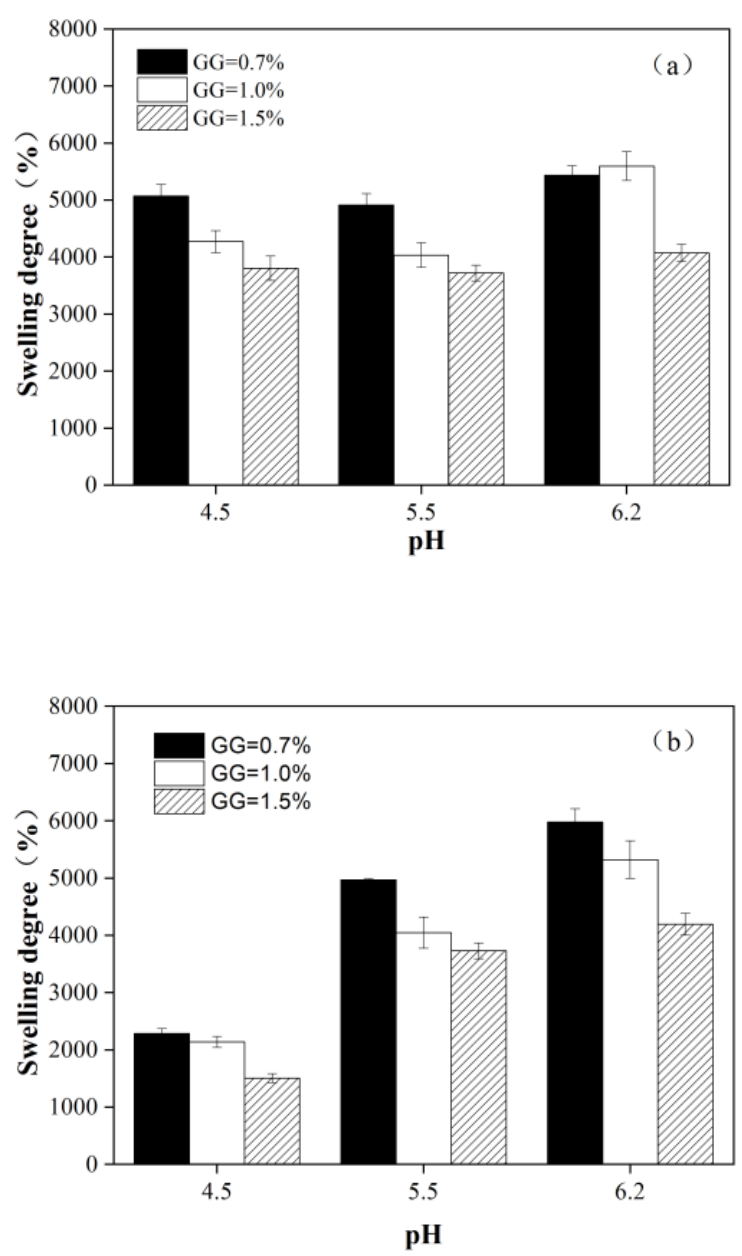

Figure 2. Effect of preparation conditions on swelling degrees of GG-CS microcapsules (a:CS=0.7\%; $\mathrm{b}: \mathrm{CS}=1.0 \%)$
It can be seen from Figure 2 that, under the condition of constant chitosan concentration, the concentration of gellan gum had a significant influence on the swelling degree of gellan gumchitosan microcapsules. When the concentration of chitosan is constant, the swelling degree of microcapsules decreases with the increase of gellan gum concentration.

When the concentration of chitosan solution is $1 \%$, the influence of chitosan $\mathrm{pH}$ on the swelling degree is more significant than that when the concentration of chitosan is $0.7 \%$. When $\mathrm{pH}$ increased from 4.5 to 6.2 , the swelling degree increased significantly. When the concentration of chitosan was $0.7 \%$ and the $\mathrm{pH}$ increased from 4.5 to 6.2 , the swelling degree of microcapsules showed a trend of decreasing first and then increasing. When the $\mathrm{pH}$ of chitosan increased from 4.5 to 5.5, the significant increase in swelling degree might be related to a slight reduction of chitosan charge density, thus the ionic bond between polymers become weak, leading to a higher swelling degree (Magnin et al., 2017). The influence of the chitosan concentration on the swelling degree of the microcapsules was not as obvious as the concentration of gellan gum solution and the chitosan solution $\mathrm{pH}$. Lee studied the swelling characteristic of chitosan/sodium tripolyphosphate chelating resin and explored the relationship between the density of the internal complex structure of microcapsules and the sensitivity to $\mathrm{pH}$ of the solution. They found that the microcapsules with the loose structures were more sensitive to $\mathrm{pH}$ (Lee et al., 2001). Because the swelling degree of microcapsules is sensitive to $\mathrm{pH}$, the microcapsules can achieve sustained release in the intestinal tract and reduce the impact of the acidic environment of the gastrointestinal tract.

\section{Effect of chitosan concentration on encapsulation yield of Lactobacillus casei L61 microcapsules}

L. casei L61 was encapsulated by extrusion at different concentrations of chitosan $(0.25 \%, 0.50 \%$, $0.75 \%, 1.00 \%$ ), and the viable cells and encapsulation yield of unit mass gellan gumchitosan L.casei L61 microcapsule were determined. The results are shown in Figure 3.

The main reason for the influence of chitosan concentration on the performance of microcapsules is that changing the concentration of chitosan solution will lead to the change of molecular diffusion rate, thus affecting the film forming effect. Figure 3 shows that the concentration of chitosan remarkably affects the viable cells and 
encapsulation yield of L.casei L61. When the concentration of chitosan was less than $0.50 \%$, the viable cells and the encapsulation yield of microcapsules per unit mass would increase with the increase of the concentration of chitosan. When the concentration of chitosan is low, the viscosity of the solution is small, and the solution can be uniformly dispersed in the outer layer of gellan gum. The gel structure formed by the action of the amino groups in the chitosan molecules and the carboxyl groups in the gellan gum molecules is less dense, and the crosslinking degree between the wall materials is reduced, resulting in a large amount of L.casei L61 leaking out during the stirring process. When the concentration of chitosan increased to $0.50 \%$, the viable cells and the encapsulation yield of L.casei L61 reached the maximum. Increasing the concentration of chitosan helps to strengthen the diffusion driving force of its molecules so that the number of $-\mathrm{NH}_{3}{ }^{+}$sites increase, and the positive and negative charges of the two are more fully combined, and the degree of crosslinking between chitosan and gellan gum is stronger. The degree of crosslinking becomes stronger, the denseness of the formed network structure is strengthened, and the leakage of the bacteria in the microcapsule is also reduced. The viable cells and encapsulation yield of L.casei L61 will also increase (Maurstad et al., 2010). However, when the concentration of chitosan continues to increase, the viable cells and encapsulation yield of the microcapsules decrease significantly, because the viscosity of chitosan will increase as the concentration of chitosan increases. The continuous increase of viscosity will change the rheological properties.

Chitosan will form autopolymers, which will reduce the diffusion rate of molecules and make them unable to disperse evenly in the outer layer of gellan gum, so the cross-linking effect between chitosan and gellan gum is correspondingly weakened. After the weakening of crosslinking effect, chitosan could not form dense gellan gum-chitosan composite film with gellan gum, and the improvement of gel bead permeability was not good, leading to a decrease in both the viable cells and encapsulation yield per unit mass of microcapsules (Verma et al., 2011).

The experiment finally showed that the suitable chitosan concentration was $0.50 \%$, and the viable cells per unit mass of L.casei L61 microcapsules was $9.71 \log$ CFU/g and the encapsulation yield was $76.50 \%$.

\section{Selection of $\mathrm{pH}$ value of chitosan and its influence on the embedding effect of microcapsules}

Chitosan was used to encapsulate L.casei L61 under $\mathrm{pH}(4.0,4.5,5.0,5.5,6.0)$ conditions, and the properties of the prepared gellan gum-chitosan L.casei L61 microcapsules were shown in Figure 4. The $\mathrm{pH}$ of the chitosan solution directly affects the ionization degree of the chitosan solution, thereby affecting the surface charge properties and strength of the chitosan and gellan gum molecules, and ultimately affecting the formation of gellan gumchitosan microcapsules. The pKa value of chitosan is generally about 6.5 . Under acidic conditions, the amino group on the molecule is protonated and positive. In the process of microencapsulation, the $\mathrm{pH}$ of the system is generally controlled between 36. Figure 4 shows that the viable cells and encapsulation yield of L.casei L61 was remarkably affected by chitosan $\mathrm{pH}$. When the $\mathrm{pH}$ is in the

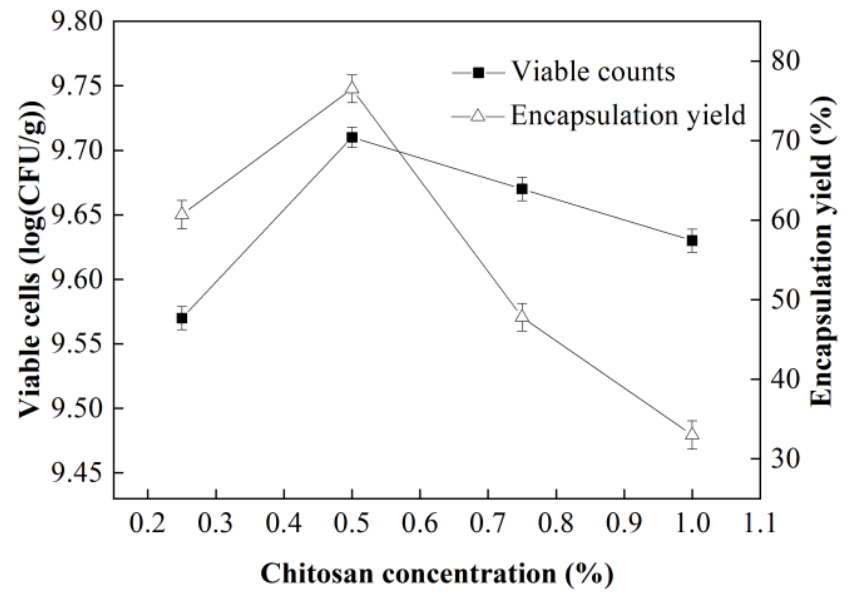

Figure 3. Effects of CS concentration on viable cells and encapsulation yield of $L$. casei L61.

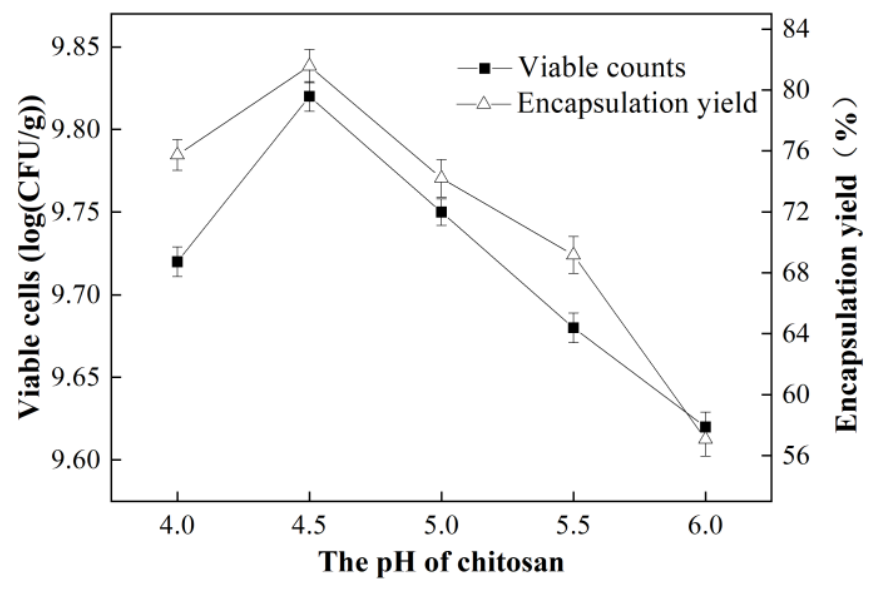

Figure 4. Effects of CS pH on viable cells and encapsulation yield of $L$. casei $\mathrm{L} 61$. 
range of 4.0-4.5, the viable cells and encapsulation yield of L.casei L61 per unit mass are positively correlated with the $\mathrm{pH}$ of chitosan, and the viable cells and the encapsulation yield of microcapsule reach the maximum at $\mathrm{pH} 4.5$. When $\mathrm{pH}$ was in the range of 4.5-6.0, the viable cells and the encapsulation yield of L.casei L61 per unit mass were negatively correlated with the $\mathrm{pH}$ of chitosan. When the $\mathrm{pH}$ of chitosan is close to the $\mathrm{pKa}$ value, the ionization and solubility of chitosan are weakened, and the number of positive charges carried by the amino group is reduced. The decrease in charge density further affects the interaction between chitosan and gellan gum. The degree of crosslinking is reduced, and the formed network structure becomes loose, resulting in a large amount of leakage of probiotics in the microcapsules (Norton et al., 2011).

The optimum $\mathrm{pH}$ value of chitosan solution was 4.5, and the viable cells and the encapsulation yield of L.casei L61 per unit weight were $9.72 \log \mathrm{CFU} / \mathrm{g}$ and $80.57 \%$.

\section{Effect of gellan gum concentration on embedding effect}

The different gellan gum concentration $(1.00 \%$, $1.25 \%, 1.50 \%, 1.75 \%)$ was selected to study the effect of the concentration on the preparation of gellan gum-chitosan L.casei L61 microcapsule. The result is shown in Figure 5. When the gellan gum concentration was less than $1.50 \%$, the viable cells and the encapsulation yield of microcapsules was positively correlated with the concentration of gellan gum. When the concentration was $1.50 \%$, the viable cells and the encapsulation yield of L.casei L61 reached the maximum. However, continuing to increase the concentration of gellan gum will lead to the decrease of the viable cells and the encapsulation yield per unit mass of microcapsules. The gellan gum concentration directly affects the viscosity, thus affecting the elasticity and texture of microcapsules. As the concentration of gellan gum increases, the viscosity of gellan gum increases and the intermolecular interaction increases, which is conducive to the formation of a more compact threedimensional network structure. The compact threedimensional network structure can effectively prevent L.casei L61 from leaking from the microcapsules, and the mechanical strength of the prepared microcapsules is significantly improved, thus improving the encapsulation yield (Agnihotri et al., 2006). The continuous increase of gellan gum concentration will make the solution viscosity too high, thus increasing the difficulty of complexation between gellan gum and chitosan. Besides, it is easy to block the needle, and the experiment is inconvenient. The shape of gellan gum-chitosan microcapsules prepared under these conditions is irregular.

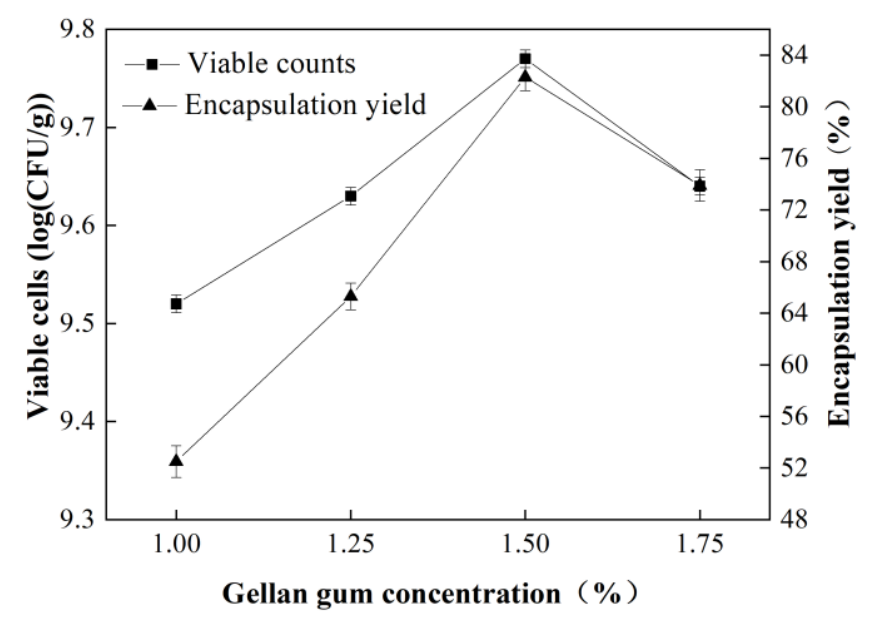

Figure 5. Effects of GG concentration on viable cells and encapsulation yield of $L$. casei L61.

Finally, it was determined that $1.50 \%$ gellan gum solution was the most suitable for preparing gellan gum-chitosan L.casei L61 microcapsule. The viable cells and encapsulation yield per unit mass of L.casei L61 microcapsule were $9.77 \log$ CFU/g and $82.30 \%$.

\section{Effect of the VRBS to gellan gum on encapsulation yield}

The different VRBS to gellan gum $(1: 2,1: 4,1: 6,1: 8)$ was selected to explore how the VRBS to gellan gum affect the preparation of gellan gum-chitosan L.casei L61 microcapsule. The result is shown in Figure 6. When the volume ratio changed from 1:2 to $1: 4$, the viable cells decreased and the encapsulation yield increased. When the volume ratio is $1: 2$, it may be because gellan gum occupies a small proportion in the mixed solution, the negative charge carried by the carboxyl group of gellan gum and the positive charge carried by the amino group of chitosan does not interact completely through ions, resulting in the network structure is not dense enough, and the embedded bacteria are few, so the encapsulation yield is relatively low. The microcapsules prepared by the small volume of the mixed solution are light in weight, and the viable cells per unit mass of microcapsules are higher. 


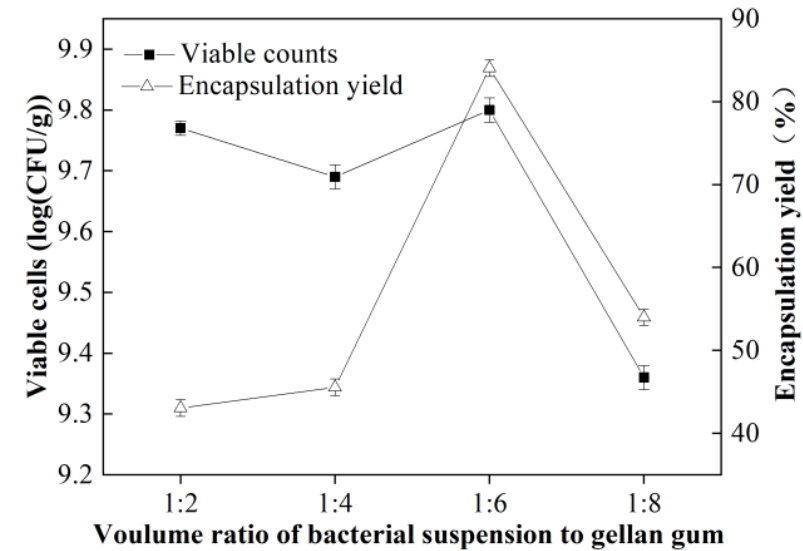

Figure 6. Effect of bacterial suspension/GG on viable cells and encapsulation yield of $L$. casei L61.

When the volume ratio changed from 1:4 to $1: 6$, the viable cells and the encapsulation yield of L.casei L61 showed an upward trend. When the volume ratio was 1:6, both the viable cells and the encapsulation yield reached the maximum. Increase the proportion of gellan gum, gellan gum, and chitosan form a denser network structure, reducing the leakage of bacteria. When the volume ratio continued to increase, the viable cells and the encapsulation yield of microcapsules showed a downward trend. When the proportion of gellan gum is too large, the formed microcapsules will form a thicker outer layer, resulting in a reduction of the number of bacteria embedded in the microcapsules, and a decrease in the viable cells and the encapsulation yield.

The experiment determined that when the VRBS to gellan gum was 1:6, the viable cells and the encapsulation yield per unit mass of L.casei L61 microcapsules were the highest, which were 9.80 $\log$ CFU/g and $84.05 \%$, respectively.

\section{Effect of VRBG to chitosan on the performance of microcapsules}

The different VRBG to chitosan (1:3, 1:4, 1:5, 1:6) was selected to explore how the VRBG to chitosan affect the preparation of gellan gum-chitosan L.casei L61 microcapsules. The result is shown in Figure 7. The viable cells per unit weight and the encapsulation yield of L.casei L61 microcapsules changed with the change of the VRBG to chitosan.

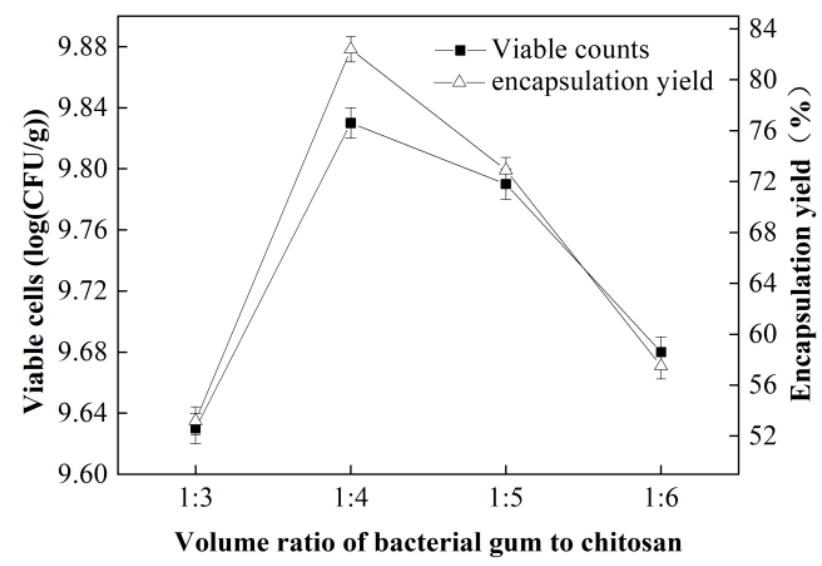

Figure 7. Effects of (L.casei-GG mixture)/CS on viable cells and encapsulation yield of $L$. casei L61.

When the volume ratio changed from $1: 3$ to $1: 4$, both the viable cells and encapsulation yield of L.casei L61 were increased and reached the maximum value when the volume ratio was $1: 4$. When the volume of chitosan increased, gellan gum could cross-link with chitosan to form a dense network structure, which could effectively prevent the leakage of bacteria, and the viable cells and the encapsulation yield of microcapsules increased. When the volume ratio changed from 1:4 to $1: 6$, the viable cells and the encapsulation yield of L.casei L61 showed a decreasing trend. As the volume of chitosan continues to increase, the thickness of the chitosan coating will be increased, and the viable cells and the encapsulation yield will decrease.

The experiment determined that when the VRBG to chitosan was 1:4, the viable cells and the encapsulation yield of L.casei L61 were the highest, which were $9.83 \log$ CFU/g and $82.4 \%$, respectively.

\section{Effect of stirring time on the properties of microcapsules}

The stirring time (20min, 30min, 40min, 50min) was selected to study the effect of preparing gellan gum-chitosan L.casei L61 microcapsules. After the embedding of L.casei L61, the viable cells and the encapsulation yield of unit weight microcapsule were measured, and the results were shown in Figure 8. The viable cells and the encapsulation yield of L.casei L61 changed with the change of stirring time. When the stirring time was less than $40 \mathrm{~min}$, both the viable cells and the encapsulation yield of microcapsules increased with the prolonging of stirring time. When the agitation was 
insufficient, the surface of the microcapsules was rapidly cross-linked, and the COO-group of gellan gum was not completely combined with the $\mathrm{NH}_{3}{ }^{+}$ group of chitosan, resulting in a thin outer film, which affected the embedding effect

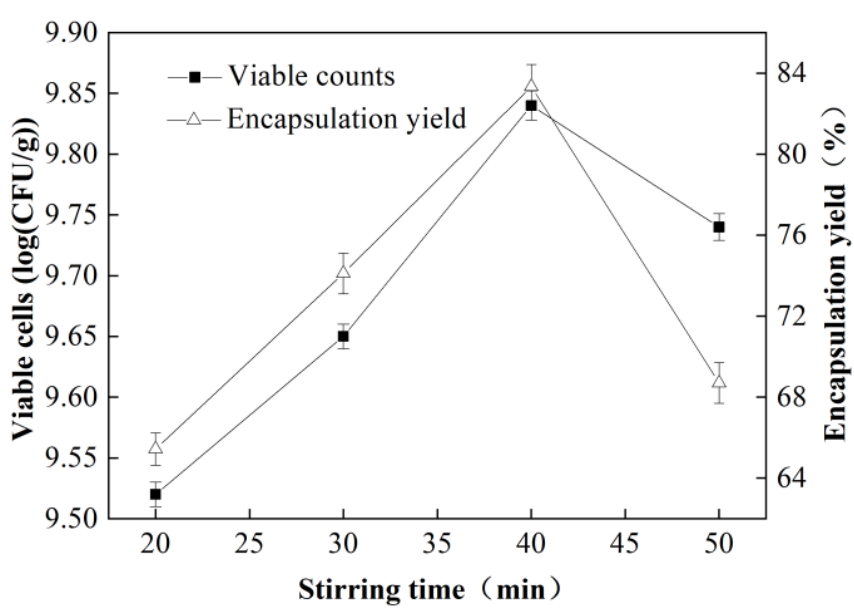

Figure 8. Effects of stirring time on viable cells and encapsulation yield of $L$. casei $L 61$.

\section{CONCLUSION}

This experiment proves that it is feasible to use chitosan and gellan gum as wall material of microcapsule. Through a single factor experiment, the law of the viable cells and the encapsulation of microcapsules varied with each factor was obtained, and the optimum value of each factor was determined: Chitosan concentration $0.50 \%$, the $\mathrm{pH}$ value of chitosan solution is 4.5 , gellan gum
When the stirring time is prolonged, the dense network structure can be formed between gellan gum and chitosan. When the stirring time was $40 \mathrm{~min}$, the viable cells and the encapsulation yield reached the maximum. If the stirring time was prolonged, the network structure of gellan gumchitosan polyelectrolyte hydrogel would be destroyed, which further affected the density of the microcapsules, resulting in new leakage of bacteria into the chitosan solution, and the viable cells and the encapsulation yield showed a decreasing trend.

The results showed that the optimal stirring time was $40 \mathrm{~min}$. The viable cells and encapsulation yield of L.casei L61 were $9.84 \log$ CFU/g and 83.33\% respectively.

\section{ACKNOWLEDGEMENTS}

This work was partially surported by the Key Research and Development Program of Shaanxi (Program No.2019ZDLNY06-01).

\section{REFERENCES}

1. Argin-Soysal, S., Kofinas, P. \& Lo, Y. M. (2009). Effect of complexation conditions on xanthan-chitosan polyelectrolyte complex gels. Food Hydrocolloids, 23(1), 202-209. DOI: 10.1016/j.foodhyd.2007.12.011.

2. Argin, S., Kofinas, P. \& Lo, Y. M. (2014). The cell release kinetics and the swelling behavior of physically crosslinked xanthan-chitosan hydrogels in simulated gastrointestinal conditions. Food Hydrocolloids, 40(oct.), 138-144.

DOI: 10.1016/j.foodhyd.2014.02.018

3. Agnihotri, S. A., Jawalkar, S. S. \& Aminabhavi, T. M. (2006). Controlled release of cephalexin through gellan gum beads: effect of formulation parameters on entrapment efficiency, size, and drug release. European Journal of Pharmaceutics \& Biopharmaceutics, 63(3), 0-261. 
DOI: 10.1016/j.ejpb.2005.12.008.

4. Fareez, I. M., Lim, S. M., Mishra, R. K. \& Ramasamy, K. (2015). Chitosan coated alginate-xanthan gum bead enhanced $\mathrm{pH}$ and thermotolerance of lactobacillus plantarum lab12. International Journal of Biological Macromolecules, 72, 1419-1428.

DOI: 10.1016/j.ijbiomac.2014.10.054.

5. Gareth, Gordon, Syngai, Ragupathi, Gopi \& Rupjyoti, et al. (2016). Probiotics - the versatile functional food ingredients. Journal of Food Science\&Technology, 53(2), 921-933.

DOI: $10.1007 / \mathrm{s} 13197-015-2011-0$.

6. Islam \& Ariful, M. (2010). Microencapsulation of live probiotic bacteria. Journal of Microbiology \& Biotechnology, 20(10), 1367-1377. DOI: 10.4014/jmb.1003.03020.

7. Kekkonen, R. A., Sysi-Aho, M., Seppanen-Laakso, T., Julkunen, I., Vapaatalo, H. \& Oresic, M., et al. (2008). Effect of probiotic Lactobacillus rhamnosus GG intervention on global serum lipidomic profiles in healthy adults. World Journal of Gastroenterology, 14(020), 3188-3194.

DOI: $10.3748 /$ wjg.14.3188.

8. Lee, J. S., Cha, D. S., \& Park, H. J. (2005). Survival of freeze-dried Lactobacillus bulgaricus KFRI 673 in chitosan-coated calcium alginate microparticles. Journal of Agricultural and Food Chemistry, 52(24), 7300-7305. DOI: 10.1021/jf040235k.

9. Lee, S. T., Mi, F. L., Shen, Y. J. \& Shyu, S. S. (2001). Equilibrium and kinetic studies of copper(ii) ion uptake by chitosan-tripolyphosphate chelating resin. Polymer, 42(5), 1879-1892. DOI: 10.1016/S00323861(00)00402-X.

10. Magnin D, Lefebvre J, Chornet E, et al. (2017). Structural, thermal, physical, mechanical, and barrier properties of chitosan films with the addition of xanthan gum. Journal of Food Science, 82(3). DOI: 10.1111/1750-3841.13653.

11. Martín, María José, Lara-Villoslada, F., Ruiz, María Adolfina \& Morales, María Encarnación. (2015). Microencapsulation of bacteria: a review of different technologies and their impact on the probiotic effects. Innovative Food Science \& Emerging Technologies, 27, 15-25. DOI: 10.1016/j.ifset.2014.09.010.

12. Maurstad, G., Bausch, A. R., Sikorski, P. \& Bjørn T. Stokke. (2010). Electrostatically self-assembled multilayers of chitosan and xanthan studied by atomic force microscopy and microinterferometry. Macromolecular Symposia, 227(1), 161-172.

DOI: 1010.1002/masy.200550916.

13. Norton, A. B., Cox, P. W., \& Spyropoulos, F. (2011). Acid gelation of low acyl gellan gum relevant to self-structuring in the human stomach. Food Hydrocolloids, 25(5), 1105-1111.

DOI: 10.1016/j.foodhyd.2010.10.007.

14. Sarkar, S. (2010). Approaches for enhancing the viability of probiotics: a review. British Food Journal, 112(4), 329-349. DOI: 10.1108/00070701011034376.

15. Solanki, H. K., Pawar, D. D., Shah, D. A., Prajapati, V. D., Jani, G. K. \& Mulla, A. M., et al. (2013). Development of microencapsulation delivery system for long-term preservation of probiotics as biotherapeutics agent. BioMed Research International, 2013, 620719. DOI: 10.1155/2013/620719.

16. Sultana, K., Godward, G., Reynolds, N., Arumugaswamy, R., Peiris, P. \& Kailasapathy, K. (2000). Encapsulation of probiotic bacteria with alginate-starch and evaluation of survival in simulated gastrointestinal conditions and in yoghurt. International Journal of Food Microbiology, 62(1-2), 47-55. DOI: $10.1016 /$ S0168-1605(00)00380-9.

17. Sun, W. \& Griffiths, M. W. (2000). Survival of Bifidobacteria in yoghurt and gastric juice following immobilization in gellan-xanthan beads. International Journal of Food Microbiology, 61(1), 17-25.

DOI: 10.1016/S0168-1605(00)00327-5.

18. Verma, A., Dixit, R., Singh, U. P., Soni, S. \& Pandit, J. K. (2011). Preparation and characterization of gellan-chitosan polyelectrolyte complex beads. LATIN AMERICAN JOURNAL OF PHARMACY, 30(6), 1186-1195. 
19. Vishwanathan, K. H., Singh, V., \& Subramanian, R. (2011). Wet grinding characteristics of soybean for soymilk extraction. Journal of Food Engineering, 106(1), 28-34. DOI: 10.1016/j.jfoodeng.2011.04.002.

20. WHO/FAO. (2001). Evaluation of health and nutritional properties of powder milk and live lactic acid bacteria. Food and Nutrition Paper, 71. 